\title{
POPULATION FLUCTUATION, BIOLOGICAL FEATURES OF DUBAS BUG (Ommatissus lybicus DeBerg (HOMOPTERA :TROPIDUCHIDAE) ATTACKING DATE PALM TREES (Phoenix dactylifera L.) AND ITS BIOLOGICAL CONTROL BY Chrysoperla carnea (Steph.) LARVAE.
}

Hussain, A. E. ${ }^{1}$; S. A. El-Arnaouty ${ }^{2}$; Kh. M. Ghanem ${ }^{3}$ and M. S. Al-Anany ${ }^{3}$

1- Economic Entomology Dept.,Fac.Agric.,Al-Azhar Univ.,Cairo

2- Economic Entomology Dept., Fac. of Agric., Cairo Univ., Giza

3- Environ. and Bio-Agric. Dept., Fac. of Agric., Al-Azhar Univ., Cairo,

\begin{abstract}
The Palm trees, attacking by many insect pests and among the most important of these insect pests Dubas bug Ommatissus lybicus DeBerg (Homoptera: Tropiduchidae ). The study of the population fluctuation of Dubas bug $O$. lybicus was carried out in Helwan on date palms in correlation with studying associated natural enemies. Field studies were carried out during two successive seasons $(2010 / 2011$ and $2011 / 2012)$ by fortnightly visits to examine the fronds of the selected palms. The data showed that there are two generations per every year (spring and autumn generations) on Date palm trees. There was a negative correlation between Dubas numbers and each of temperature and relative humidity. There was no significant differences between the two seasons. The most widely spread predators were Chrysoperla carnea (Steph.), Coccinella undecimpunctata L., Sphodromantis sp. As respect to biological studies on dubas bug, O. lybicus were carried out in 2009. The obtained results showed that the insect pest had two annual generations (spring and autumn generations) and the adult passed through five nymphal instars before maturity. The spring generation lasted $166.5 \pm 12.85$ days, while autumn generation lasted $145 \pm 6.20$ days. The nymphal stage lasted $53.5 \pm 1.87$ days for the spring generation and $51.5 \pm 1.87$ days for the autumn generation. Adult females lived $63 \pm 5.6$ days and $91.4 \pm 13.6$ days in spring and autumn generations, respectively. The respective figures for males were $33.5 \pm 6$ and $76 \pm 9$ days. The number of deposited eggs ranged from $146.5 \pm 8.23$ eggs/female for the spring generation to $146.5 \pm 2.45$ eggs/female in autumn generation. The incubation period of the egg stage reached $117.5 \pm 1.87$ days and $60 \pm 3.32$ days for spring and autumn generations, respectively. Statistical analysis showed that there were significant differences between developmental time means of eggs and adults for both generations. Results also showed that there were significant differences between spring and autumn life span periods (235.5 \pm 16.30 and $164 \pm 9.09$ days, respectively). Nymphal stage of dubas bug showed five developmental instars with five moulting, with significant differences recorded among means of developmental periods among nymphal instars $(8.5 \pm 1.29,10.5 \pm 1.29,13 \pm 1,11.5 \pm 1.29,14 \pm 1$ and $8 \pm 1,8.5 \pm 1.29,12 \pm 1,13 \pm 1$ $13.5 \pm 1.29$ days) for spring and autumn generations, respectively. The results showed significant differences between male and female longevities for both generations. The biological control of dubas bug by Ch.carnea Larvae, showed that the Ch. carnea larvae has the ability to consume average $16.4 \pm 6.9$ nymphs of the first nymphal instar of dubas bug during 24 hours.
\end{abstract}


Hussain, A. E. et al.

\section{INTRODUCTION}

The date palm (Phoenix dactylifera L.) is considered a symbol of life in the desert, because it tolerates high temperatures, drought and salinity more than many other fruit crop plant species, it is one of the oldest trees from which man has derived benefit. And it has been cultivated since ancient times. It is the only indigenous wild desert plant definitely domesticated in its native harsh environments (Zohary and Hopf, 2000). The date palm retains its value for cultivators as it gives a wide range of products and services, including many necessities of life. The date, primary product of the palm, is rich in protein, vitamins, and mineral salts. That is why it represents an essential element of diet for the cultivator himself and his animals. All secondary products of the palm result from annual pruning and have essential uses for the cultivator. Unfortunately, the date palms grown in the Arab region are under threat from diseases, pests, environmental changes and socio-economic factors. Of the estimated 120 million date palms in the world, over two-thirds are in Arab countries (FAO, 1982).

Arab countries possess $70 \%$ of the 120 million world's date palms and are responsible for $67 \%$ of the global date production (EL-Juhany, 2010).

Dubas bug $O$. lybicus, is a serious pest of date palm in the Sultanate of Oman. It has been recorded in Bahrin ( El - Haidari , 1981); in Sudan ( El Haidari, 1982 ); in Israel ( Klien and Venezian,1985); in Qatar (Al - Azawi, 1986); in many Arab countries (El-Haidari and AlHafidh, 1986); in date palm plantations in Iraq, Iran, Egypt, N. Africa (Hill and Waller, 1990); in Egypt (Hussein and Ali,1996) and in Libya ( Lal and Naji, 1997). Dubas bug was recorded for the first time as a pest attacking young Date palm and Canary palm in Helwan governorate in April 2007, it was found to attack green fronds of the palm (Hussain, 2011). O. lybicus was referred to in earlier literature as the "lybicus" variety of $O$. binotatus it was raised to species status by Asche and Wilson (1989). O. lybicus is known in Arab area as "Dubas bug", and in some literature it is known as the "Old world date bug". This species is restricted to date palm on which it completes its life cycle. The infested date palm with $O$. lybicus, affected directly through the feeding of the mobile stages of this insect, and indirectly by producing copious amounts of honeydew, which then covers the fronds of the date palm. The deposited honeydew accumulates, supporting sooty mould growth, and under the rainless conditions of the desert (where date palm usually grow) a thick layer of dust may accumulate on honeydew-coated surfaces. After following the infestation, sometimes the frond surfaces tend to become chlorotic. In Iraq, losses of $50 \%$ of the date crop have been attributed to this insect (Kranz et al., 1978). Dates of infested palms are reported to be smaller and to ripen slowly, with high percentage of reducing sugars and sucrose (Hussain, 1985).

The present study was carried out to shed light on the occurrence, population density and bionomic observation of dubas bug and associated 
natural enemies on date palm in Helwan city. A biological study of dubas bug has to be undertaken in order to enable proper plant protection measures at critical stages of the life cycle of the pest. It also aimed to studying the biological control for dubas bug by the predator Ch. carnea larvae under laboratory conditions.

\section{MATERIALS AND METHODS}

\section{Study the population fluctuation of dubas bug O.lybicus. on date} palm trees:

1. To study the population fluctuation of dubas bug O. lybicus, Thirty-two pinnates (replicates) of date palm trees infested by this insect, were selected in Helwan university court. Cairo Governorate. The numbers of eggs, nymphs and adults were counted fortnightly on four random pinnate per one frond, four fronds for each palm tree (one frond from each cardinal direction of the date palm tree), the number of each stage was recorded. The numbers of predators were recorded as well; these counts extended from March 2010 till March 2012, no control measures were applied for the inspected date palm (Hussain, 2011).

2. Data of the climatic factors was taken from Central Laboratory of Agricultural Climate.

3. Statistical analysis was carried out (correlation coefficient and $T$ values).

Biological aspects of $\boldsymbol{O}$. lybicus under semi field conditions:

1. Biological studies for the spring and autumn generations of dubas bug were carried out in 2009 on 10 date palm seedlings cultivated in plastic pots $(25 \mathrm{~cm}$ diameter $\times 25 \mathrm{~cm}$. height) under semi field conditions.

2. Samples of Dubas bug adults were collected from the date palm at Helwan University Cairo Governorate in late November (autumn generation) in 2008.

3. The date palm seedlings were infested by dubas bugs adult, then covered with plastic cages displaying two muslin windows on the two sides for ventilation.

4. During the following days, the date palm seedlings were examined carefully to monitor newly egg-laying then the newly hatched nymphs. The duration of the nymphal instars were estimated. The adults were inspected daily until death. Longevity of adults (males \& females), pre-oviposition, oviposition, post oviposition, life span periods and number of deposited eggs/female were estimated. Deposited eggs were left until hatching and the incubation period was determined.

5. Statistical analysis was carried out (T values).

Food consumption of $\mathrm{Ch}$. carnea larvae from dubas bug nymphs:

1. The experiment was carried out on cultivated date palm seedlings in plastic pots $(10 \mathrm{~cm}$ diameter $\times 15 \mathrm{~cm}$. height) consisting of (5 replicates and 1 control) under laboratory conditions $\left(25^{\circ} \mathrm{c}, 60 \%\right.$ R.H).

2. Rearing of $\mathrm{O}$. lybicus in Faculty of Agriculture, AlAzhar University. Culture of $O$. lybicus nymphs were reared on cultivated palm seedlings cultivated in plastic pots. 
Hussain, A. E. et al.

3. Rearing of Ch. carnea at the Chrysopa mass rearing unit, Faculty of Agriculture, Cairo University. Culture of $\mathrm{Ch}$. carnea larvae were reared on Ephestia kuehnilla eggs.

4. Each date palm seedling and the control were infested by 50 dubas bug nymphs ( $1^{\text {st }}$ instar). Then provided by $C h$. carnea larva $2^{\text {nd }}$ instar (one larva / one seedling) except for the control.

5. On the following day survival rate of dubas nymphs, was estimated $C h$. carnea larva, rate of food consumption in 24 hours were calculated and compared to that of the control. The larvae were inspected daily until they reached pupal stage then the number of Ch. carnea at pupal stage were estimated.

\section{RESULTS AND DISCUSSION}

\section{Population fluctuation of dubas bug:}

Eggs, nymphs and adults were observed on green leaflets, females laid eggs on the midrib of the leaves and on the blade and the vein of the leaflets.

\section{Population fluctuation of dubas bug in the first season 2010/ 2011:}

Data presented and illustrated by (Figure 1) show that acertain number of eggs were found during two periods; the first period occurred through July 2010 with an average maximum density of 9 eggs / 32 leaflets on date palm, the second one recorded through the last months of 2010 with an average maximum density of 12.75 eggs / 32 leaflet on date palm during December (Fig. 1).

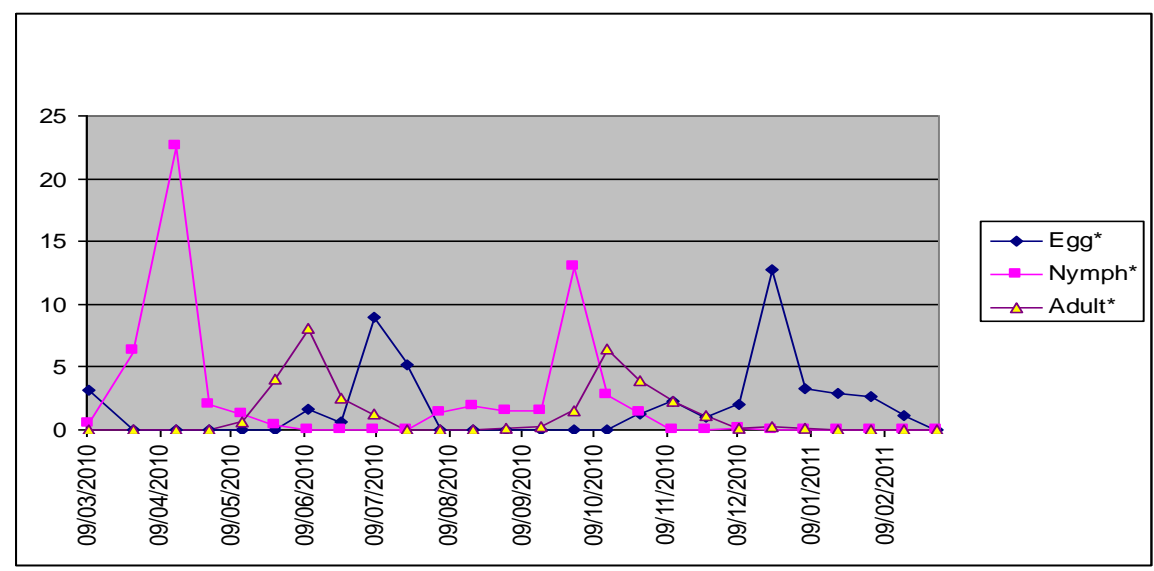

Fig.1. Population fluctuation of different stages of dubas bug Ommatissus lybicus DE BERG on date palm trees during 2010/2011.

Nymphs were recorded on date palm in higher numbers (22.59 nymphs $/ 32$ leaflets) on the $15^{\text {th }}$ of April 2010, these numbers decreased gradually to disappear in July 2010, the nymphs appeared in August (1.34 
nymphs /32 leaflets) and increased gradually to reach a peak in September. 2010, (13 nymphs /32 leaflets), then decreased gradually to disappear through the period extending from the first of January 2011 till the first week of March 2012 (Fig. 1).

As regard to adult stage on date palm, it was recorded on the $27^{\text {th }}$ of May 2010 and the first peak of adult population density (8.03 adults /32 leaflets) occurred on the $10^{\text {th }}$ of June. 2010, another peak (6.46 adults / 32 leaflets) was recorded on the $14^{\text {th }}$ of Octoper 2010 . Generally the adult stage was found throughout the various examination periods (Fig. 1).

Population fluctuation of dubas bug in the second season 2011/ 2012:-

Data presented and illustrated by (Figure 2) showed that the density of the different stages of dubas bug during 2011 / 2012 displays the same trend as that of $2010 / 2011$ approximately.

The first period of egg laying extended from $23^{\text {rd }}$ of June to $4^{\text {th }}$ of August 2011 with a maximum density of 10.59 eggs /32 leaflets during July, while the second period extended from October 2011 till February 2012 on the date palm with a maximum density of 6.37 eggs /40 leaflets during December 2011 on date palm.

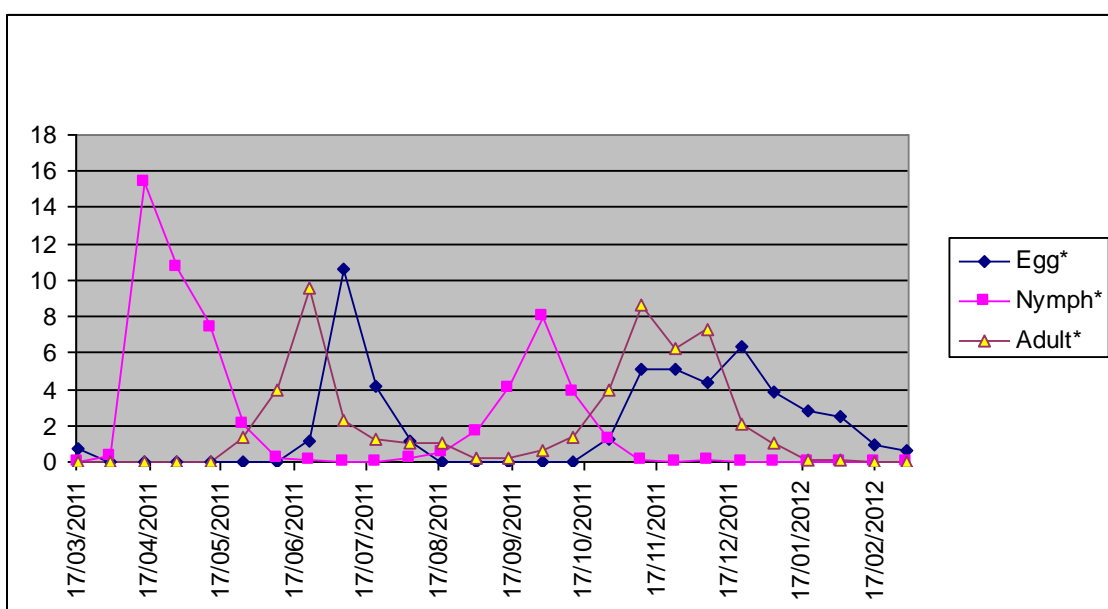

Fig.2. Population fluctuation of different stages of dubas bug Ommatissus lybicus DE BERG on date palm trees during 2011/2012.

Two population peaks of nymphs were recorded on date palm, the first peak 15.43 nymphs / 32 leaflets during April 2011, the second one 8.06 nymph / 32 leaflets on date palm during September 2011.

As respect to adult stage it occurred throughout the year and there were two peaks recorded, the first peak (9.62 adults /32 leaflets on date palm occurred during Jun. 2011 and the second one (8.59 adults/32 leaflets on date palm) during November 2011 (Fig. 2). 
Hussain, A. E. et al.

From these data it is clear that dubas bug has two generations per year, these results agree with Hussain, 1963; Hussain and Ali, 1996; Elwan and Al-Tamiemi, 1998; Al-Shamsi, 2003 and Hussain, 2011.

Correlation between some weather factors (temperature \&R.H. \%) and dubas numbers:

(Tables 1) showed that there was an insignificant correlation between temperature \& dubas bug population densities (eggs, nymphs and adults), the same was observed between R.H.\% and dubas bug population densities (eggs, nymphs and adults) on date palm for each season 2010/2011 and 2011/2012. No significant difference could discriminate a season from the other (Table 2).

Table 1: Correlation between some climatic factors (temperature \&R.H. \%) and dubas numbers:

\begin{tabular}{|l|c|c|c|c|c|c|c|c|}
\hline \multirow{2}{*}{$\begin{array}{c}\text { Insect } \\
\text { stage }\end{array}$} & \multicolumn{3}{|c|}{ Season 2010/2011 } & \multicolumn{4}{c|}{ Season 2011/2012 } \\
\cline { 2 - 9 } & \multicolumn{2}{|c|}{ Temp. } & \multicolumn{2}{c|}{ R.H.\% } & \multicolumn{2}{c|}{ Temp. } & \multicolumn{2}{c|}{ R.H.\% } \\
\cline { 2 - 9 } & $\mathbf{r}$ & p.value & $\mathbf{r}$ & p.value & $\mathbf{r}$ & p.value & $\mathbf{r}$ & p.value \\
\hline egg & -0.303 & 0.132 & 0.083 & 0.687 & -0.204 & 0.318 & 0.476 & 0.014 \\
\hline nymph & 0.103 & 0.617 & -0.214 & 0.294 & 0.171 & 0.404 & -0.385 & 0.052 \\
\hline adult & 0.325 & 0.105 & -0.341 & 0.088 & 0.061 & 0.767 & -0.273 & 0.177 \\
\hline
\end{tabular}

Table 2:Statistical variance between different stages during (2010/2011 and 2011/2012).

\begin{tabular}{|l|c|c|c|}
\hline \multicolumn{1}{|c|}{ Comparison } & Mean Difference & T value & P value \\
\hline $\begin{array}{l}\mathbf{2 0 1 0 / 2 0 1 1} \text { eggs vs. 2011/2012 eggs } \\
\text { 2010/2011 nymph vs. 2011/2012 } \\
\text { nymph }\end{array}$ & -0.066 & -0.083 & Ns $p>0.05$ \\
\hline $\mathbf{2 0 1 0 / 2 0 1 1 ~ a d u l t ~ v s . ~ 2 0 1 1 / 2 0 1 2 ~ a d u l t ~}$ & -0.754 & 0.030 & Ns $p>0.05$ \\
\hline
\end{tabular}

Associated insect's predators:

- Many eggs, larvae and adults of Ch. carnea were recorded on date palm.

- There were some adults of $C$. undecimpunctata on date palm.

- There were eggs and adults of Sphodromantis $s p$ on date palm.

Biological aspects of dubas bug (Ommatissus lybicus DE BERG) under semi field conditions in 2009:

The results obtained revealed that O.lybicus had two generations/per year (spring and autumn generations) and the nymphs passed through five nymphal instars.

Spring generation:

The eggs hatching started in the third week of April and continued until last week of May and the incubation period was 115-120 days with an average of $117.5 \pm 1.87$ days at $24.5 \pm 1.87^{\circ} \mathrm{C}$ and $62.5 \pm 4.18 \%$ R.H. As presented in (Table 3 ), the nymphal stage lasted 51-56 days with a mean of $53.5 \pm 1.87$ days in semi field conditions of. The adult female started egg laying in the fourth week of May and continued until the first week of July. The pre-oviposition averaged $10.7 \pm 1.7$ days at $27.9 \pm 2^{\circ} \mathrm{C}$ and $45.9 \pm 5.6 \%$ R.H, oviposition period averaged $43.8 \pm 6.5$ days at $29.9 \pm 13.1^{\circ} \mathrm{C}$ and $50.3 \pm 13 \% \mathrm{RH}$. and post-oviposition period averaged $11 \pm 3$ days at $30 \pm 1.5^{\circ} \mathrm{C} \& 56 \pm 4.2 \%$ R.H. (Table 4 ) . 
The adult longevity averaged from $63 \pm 5.6$ days for females (at $30.5 \pm 0.71^{\circ} \mathrm{C} \& 46.5 \pm 8.32 \%$ R.H.) to $33.5 \pm 6$ days for males at $30.5 \pm 0.71^{\circ} \mathrm{C}$ \& $39.5 \pm 4.18 \%$ R.H. The number of deposited eggs ranged from 133 to 160 eggs with an average of $146.5 \pm 8.23$ eggs/female. The life span reached $235.5 \pm 16.30$ days at $26 \pm 3.89^{\circ} \mathrm{C}$ and $49.5 \pm 11.69 \%$ relative humidity (Table 4). The generation period extended from 145 to188 days with an average of $166.5 \pm 12.85$ days at $25.5 \pm 3.03^{\circ} \mathrm{C}$ and $59.5 \pm 4.18 \%$ relative humidity (Table 3 ).

Table 3: Biological aspects of Ommatissus lybicus DE BERG under semi field conditions in 2009 (spring generation):-

\begin{tabular}{|c|c|c|c|}
\hline Generation & \multicolumn{3}{|c|}{ Spring generation } \\
\cline { 3 - 4 } Insect stage & $\begin{array}{c}\text { Duration average } \\
\text { / days +S.E }\end{array}$ & $\begin{array}{c}\text { Average } \\
\text { T c }+ \text { S.E }\end{array}$ & $\begin{array}{c}\text { Average } \\
\text { H \%+S.E }\end{array}$ \\
\hline Incubation period & $\begin{array}{c}117.5 \pm 1.87 \\
(115-120)\end{array}$ & $24.5 \pm 1.87$ & $62.5 \pm 4.18$ \\
\hline Nymphal stsge: & \multicolumn{3}{|c|}{} \\
\hline $1^{\text {st }}$ nymphal instar & $\begin{array}{c}8.5 \pm 1.29 \\
(7-10)\end{array}$ & $24 \pm 2.7$ & $46.5 \pm 9.38$ \\
\hline $2^{\text {nd }}$ nymphal instar & $\begin{array}{c}10.5 \pm 1.29 \\
(9-12)\end{array}$ & $24.5 \pm 2.4$ & $43.5 \pm 8.22$ \\
\hline $3^{\text {rd }}$ nymphal instar & $\begin{array}{c}13 \pm 1 \\
(12-14)\end{array}$ & $25.5 \pm 3.02$ & $45.5 \pm 7.64$ \\
\hline $4^{\text {th }}$ nymphal instar & $\begin{array}{c}11.5 \pm 1.29 \\
(10-13)\end{array}$ & $28 \pm 2.23$ & $44 \pm 8.51$ \\
\hline $5^{\text {th }}$ nymphal instar & $\begin{array}{c}14 \pm 1 \\
(13-15)\end{array}$ & $28 \pm 2.16$ & $47.5 \pm 6.49$ \\
\hline Total nymphal period & $\begin{array}{c}53.5 \pm 1.87 \\
(51-56)\end{array}$ & $26 \pm 3.89$ & $46 \pm 9.66$ \\
\hline Pre-oviposition & $\begin{array}{c}10.7 \pm 1.7 \\
(9-13)\end{array}$ & $27.9 \pm 2$ & $45.9 \pm 5.6$ \\
\hline Generation period & $\begin{array}{c}166.5 \pm 12.85 \\
(145-188)\end{array}$ & $25.5 \pm 3.03$ & $59.5 \pm 4.18$ \\
\hline
\end{tabular}

Table 4: Some biological aspects of Ommatissus lybicus DE BERG adults under semi field conditions (Spring generation):

\begin{tabular}{|c|c|c|c|}
\hline \multirow[b]{2}{*}{ Adult stage } & \multirow[b]{2}{*}{$\begin{array}{l}\text { Duration average } \\
\text { / days +S.E }\end{array}$} & \multicolumn{2}{|c|}{ Climatic factors } \\
\hline & & $\begin{array}{l}\text { Average } \\
T^{\circ}+\text { S.E }\end{array}$ & $\begin{array}{c}\text { Average } \\
\mathrm{H} \%+\text { S.E }\end{array}$ \\
\hline Oviposition & $\begin{array}{c}43.8 \pm 6.5 \\
(33-50)\end{array}$ & $29.9 \pm 13.1$ & $50.3 \pm 13$ \\
\hline Post-oviposition & $\begin{array}{c}11 \pm 3 \\
(7-15)\end{array}$ & $30 \pm 1.5$ & $56 \pm 4.2$ \\
\hline Adult female longevity & $\begin{array}{l}63 \pm 5.6 \\
(55-70)\end{array}$ & $30.5 \pm 0.71$ & $46.5 \pm 8.23$ \\
\hline Adult male longevity & $\begin{array}{l}33.5 \pm 6 \\
(25-40) \\
\end{array}$ & $30.5 \pm 0.71$ & $39.5 \pm 4.18$ \\
\hline Numbers of eggs/female & $\begin{array}{c}146.5 \pm 8.23 \\
(133-160) \\
\end{array}$ & - & - \\
\hline Life span & $\begin{array}{c}235.5 \pm 16.30 \\
(208-263)\end{array}$ & $26 \pm 3.89$ & $49.5 \pm 11.69$ \\
\hline
\end{tabular}


Hussain, A. E. et al.

Autumn generation:

The eggs hatching started on the third week of August and continued until the end of September and the incubation period was 5565 days with an average of $60 \pm 3.32$ days at $29.5 \pm 1.87^{\circ} \mathrm{C}$ and $48.5 \pm 6.49 \%$ R.H. As presented in (Table 5), the -nymphal stage lasted 49-54 days with a mean of $51.5 \pm 1.87$ days under semi field conditions of $28 \pm 2.16^{\circ} \mathrm{C}$ and $53 \pm 7.53 \%$. R.H. The adult female started egg laying on the second week of October and continued until the first week of January. The preoviposition period lasted $12.4 \pm 3$ days at $25.8 \pm 1^{\circ} \mathrm{C}$ and $63.4 \pm 4 \%$ R.H, while the oviposition period averaged up to $73.6 \pm 13$ days at $23.7 \pm 3.9^{\circ} \mathrm{C}$ and $57.7 \pm 11.5 \% \mathrm{RH}$. and post-oviposition period averaged to $12.2 \pm 2.2$ days at $17.2 \pm 0.4^{0} \mathrm{C} \& 70.7 \pm 4.2 \%$ R.H. (Table 6 ).

The adult longevity reached $91.4 \pm 13.6$ days in females and $76.4 \pm 9$ days in males at $21.5 \pm 3.61^{\circ} \mathrm{C} \& 68 \pm 6.20 \%$ R.H. The number of deposited eggs ranged from 143 to150 eggs with an average of $146.5 \pm 2.45$ eggs/female. The life span average was $164 \pm 9.09$ days at $25.5 \pm 7.76^{\circ} \mathrm{C}$ and $58.5 \pm 12.26 \%$ relative humidity (Table 6). The generation period ranged from 135 to 155 days with an average of $145 \pm 6.20$ days at $26.5 \pm 0.71^{\circ} \mathrm{C}$ and $56 \pm 2.16 \%$ relative humidity (Table 5).

Table 5: Biological aspects of Ommatissus lybicus DE BERG under semi field conditions in 2009 (autumn generation):-

\begin{tabular}{|c|c|c|c|}
\hline Generation & \multicolumn{3}{|c|}{ Autumn generation } \\
\hline \multirow[b]{2}{*}{ Insect stages } & \multirow{2}{*}{$\begin{array}{c}\text { Average } \\
\text { duration / day }+ \text { S.E }\end{array}$} & \multicolumn{2}{|c|}{ Climatic factors } \\
\hline & & $\begin{array}{l}\text { Average } \\
\mathrm{T}^{\circ}+\mathrm{S} . \mathrm{E}\end{array}$ & $\begin{array}{l}\text { Average } \\
\mathrm{H} \%+\text { S.E }\end{array}$ \\
\hline Incubation period & $\begin{array}{l}60 \pm 3.32 \\
(55-65)\end{array}$ & $29.5 \pm 1.87$ & $48.5 \pm 6.49$ \\
\hline \multicolumn{4}{|l|}{ Nymphal stsge: } \\
\hline $1^{\text {st }}$ nymphal instar & $\begin{array}{l}8 \pm 1 \\
(7-9) \\
\end{array}$ & $29 \pm 1$ & $59.5 \pm 3.60$ \\
\hline $2^{\text {nd }}$ nymphal instar & $\begin{array}{c}8.5 \pm 1.29 \\
(7-10)\end{array}$ & $28.5 \pm 1.29$ & $55.5 \pm 1.87$ \\
\hline $3^{\text {rd }}$ nymphal instar & $\begin{array}{c}12 \pm 1 \\
(11-13)\end{array}$ & $28 \pm 1$ & $55.5 \pm 3.02$ \\
\hline $4^{\text {th }}$ nymphal instar & $\begin{array}{c}13 \pm 1 \\
(12-14)\end{array}$ & $29 \pm 1.58$ & $50 \pm 5.62$ \\
\hline $5^{\text {th }}$ nymphal instar & $\begin{array}{c}13.5 \pm 1.29 \\
(12-15)\end{array}$ & $26.5 \pm 1.29$ & $57 \pm 2.16$ \\
\hline Total nymphal period & $\begin{array}{c}51.5 \pm 1.87 \\
(49-54) \\
\end{array}$ & $28 \pm 2.16$ & $53 \pm 7.35$ \\
\hline Pre-oviposition & $\begin{array}{c}12.4 \pm 3 \\
(9-16) \\
\end{array}$ & $25.8 \pm 1$ & $63.4 \pm 4$ \\
\hline Generation period & $\begin{array}{l}145 \pm 6.20 \\
(135-155)\end{array}$ & $26.5 \pm 0.71$ & $56 \pm 2.16$ \\
\hline
\end{tabular}


J. Plant Prot. and Path., Mansoura Univ., Vol. 3 (6), June, 2012

\begin{tabular}{|c|c|c|c|}
\hline & & $\begin{array}{c}\text { Average } \\
\text { T c }+ \text { S.E }\end{array}$ & $\begin{array}{c}\text { Average } \\
\text { H \%+ S.E }\end{array}$ \\
\hline Oviposition & $\begin{array}{c}73.6 \pm 13 \\
(55-88)\end{array}$ & $23.7 \pm 3.9$ & $57.7 \pm 11.5$ \\
\hline Post-oviposition & $\begin{array}{c}12.2 \pm 2.2 \\
(9-14)\end{array}$ & $17.2 \pm 0.4$ & $70.7 \pm 4.2$ \\
\hline Adult female longevity & $\begin{array}{c}91.4 \pm 13.6 \\
(75-110)\end{array}$ & $21.5 \pm 3.61$ & $68 \pm 6.20$ \\
\hline Adult male longevity & $\begin{array}{c}76 \pm 9 \\
(65-87)\end{array}$ & $22 \pm 3.32$ & $62.5 \pm 3.03$ \\
\hline Numbers of eggs/female & $\begin{array}{c}146.5 \pm 2.45 \\
(143-150)\end{array}$ & - & - \\
\hline Life span & $\begin{array}{c}164 \pm 9.09 \\
(149-179)\end{array}$ & $25.5 \pm 7.76$ & $58.5 \pm 12.26$ \\
\hline
\end{tabular}

Table 6: Some biological aspects of Ommatissus lybicus adults under semi field conditions (autumn generation):

Statistical analysis showed that there were significant differences between developmental time means of eggs and adults for both generations, while there were no significant differences between nymphal development times for both generations. Results also showed that there were significant differences between spring and autumn life span periods (229.2 $\pm 11.5,193.4 \pm 9$.3days, respectively) (Table 7).

Nymphal stages of dubas bug showed five developmental nymphal instars with five moulting, with significant differences observed among means of developmental periods and nymphal instars $(8.5 \pm 1.29$, $10.5 \pm 1.29,13 \pm 1,11.5 \pm 1.29,14 \pm 1$ and $8 \pm 1,8.5 \pm 1.29,12 \pm 1,13 \pm 1$, $13.5 \pm 1.29$ days) for spring and autumn generations, respectively (Table $8)$.

The results showed significant differences between male and female longevities for both generations. The average male longevity was $33.5 \pm 6$ and $76 \pm 9$ days for spring and autumn generations, respectively. Where as average female longevity were $63 \pm 5.6$ and $91.4 \pm 13.6$ days, respectively (Table 7 ).

Results also showed that there were no significant differences between females fecundity for the two generations. The average number of eggs laid was $146 \pm 5$ eggs/female for spring and $146.5 \pm 2.45$ eggs/female for the autumn generation.

These results agree with (Al-Shamsi, 2003) but disagree with (Elwan and Al-Tamiemi, 1998) because their results were carried out under laboratory conditions.

The larvae and adults of lacewing Ch. carnea were watched in the place of study. 
Hussain, A. E. et al.

Table 7: Statistical analysis of some biological aspects of Ommatis sus lybicus:

\begin{tabular}{|c|c|c|c|c|c|c|}
\hline \multirow{3}{*}{ Generations } & \multirow{2}{*}{$\begin{array}{l}\text { Incubation } \\
\text { period }\end{array}$} & \multirow{2}{*}{$\begin{array}{c}\text { Total } \\
\text { nymphal } \\
\text { period }\end{array}$} & \multicolumn{2}{|c|}{ Adult longevity } & \multirow{2}{*}{$\begin{array}{l}\text { Generation } \\
\text { period }\end{array}$} & \multirow[b]{2}{*}{ Life span } \\
\hline & & & Male & female & & \\
\hline & & $\begin{array}{l}\text { Range+ } \\
\text { M } \pm S . E\end{array}$ & $\begin{array}{c}\text { Range+ } \\
M \pm S . E\end{array}$ & & & $\begin{array}{c}\text { Range+ } \\
M \pm S . E\end{array}$ \\
\hline Spring & $\begin{array}{l}7 \pm 1.87 \\
5-120) \\
a\end{array}$ & $\begin{array}{c}53.5 \pm 1.87 \\
(51-56) \\
A\end{array}$ & $\begin{array}{c}33.5 \pm 6 \\
(25-40) \\
b\end{array}$ & $\begin{array}{c}63 \pm 5.6 \\
(55-70) \\
b\end{array}$ & $\begin{array}{c}166.5 \pm 12.85 \\
(145-188) \\
a\end{array}$ & $\begin{array}{c}235.5 \pm 16.30 \\
(208-263) \\
a\end{array}$ \\
\hline & $\begin{array}{c}60 \pm 3.32 \\
(55-65) \\
b\end{array}$ & $\begin{array}{c}51.5 \pm 1.87 \\
(49-54) \\
A\end{array}$ & $\begin{array}{c}76 \pm 9 \\
(65-87) \\
a\end{array}$ & $\begin{array}{c}91.4 \pm 13.6 \\
(75-110) \\
a\end{array}$ & $\begin{array}{c}145 \pm 6.20 \\
(135-155) \\
b\end{array}$ & $\begin{array}{c}164 \pm 9.09 \\
(149-179) \\
b\end{array}$ \\
\hline
\end{tabular}

Means in each columns followed by different letters are significantly different from each other at $p<0.05$.

Table 8: Statistical analysis of different nymphal instars of Ommatissus lybicus:

\begin{tabular}{|c|c|c|c|c|c|}
\hline \multirow{2}{*}{ Generations } & \multicolumn{5}{|c|}{ Nymphal instars } \\
\cline { 2 - 6 } & $\mathbf{1}^{\text {st }}$ & $\mathbf{2}^{\text {nd }}$ & $\mathbf{3}^{\text {rd }}$ & $\mathbf{4}^{\text {th }}$ & $\mathbf{5}^{\text {th }}$ \\
\hline \multirow{3}{*}{ Spring } & $8.5 \pm 1.29$ & $10.5 \pm 1.29$ & $13 \pm 1$ & $11.5 \pm 1.29$ & $14 \pm 1$ \\
& $(7-10)$ & $(9-12)$ & $(12-14)$ & $(10-13)$ & $(13-15)$ \\
& $\mathrm{a}$ & $\mathrm{A}$ & $\mathrm{a}$ & $\mathrm{b}$ & $\mathrm{a}$ \\
\hline \multirow{3}{*}{ Autamn } & $8 \pm 1$ & $8.5 \pm 1.29$ & $12 \pm 1$ & $13 \pm 1$ & $13.5 \pm 1.29$ \\
& $(7-9)$ & $(7-10)$ & $(11-13)$ & $(12-14)$ & $(12-15)$ \\
& $\mathrm{a}$ & $\mathrm{b}$ & $\mathrm{a}$ & $\mathrm{a}$ & $\mathrm{a}$ \\
\hline
\end{tabular}

Means in each columns followed by different letters are significantly different from each other at $p<0.05$.

\section{Biological control of dubas bug nemph by Chrysoperla carnea (Steph.) larvae:}

The experiment include the release of one predator and a definite number of dubas bug nymphs (50 nymphs) on seedling palms planted in six plastic pots ( 5 replicates and 1 control). They were cage cover by muslin for ventilation and preventing any nymphs from escaping. The experiment examined after 24 hours to record the shortfall in numbers of dubas bug nymphs, which represents rate of food consumption by $\mathrm{Ch}$. carnea larvae on Dubas Bug nymphs. Observations continued daily until the pupal stage of Ch. carnea.

The results showed that the $\mathrm{Ch}$. carnea larvae can consume a number of dubas bug nymphs of the first instar $(20,8,21,10,23$ nymph for five replicates) with an average $16.4 \pm 6.9$ nymphs during 24 hours. Only three of Ch. carnea larvae reached to the pupal stage (Table 9)

These results agree with Al-Shamsi, (2003), who reported that the Ch.carnea Larva has the ability to consume a number of nymphs of the first instar from dubas bug nymphs with an estimated average of 26.3 nymphs in 24 hours. 
Table 9: Food consumption of Chrysopa carnea larvae from $1^{\text {st }}$ nymph Dubas bug

\begin{tabular}{|c|c|c|c|c|c|c|c|c|c|}
\hline $\mathbf{R}$ & 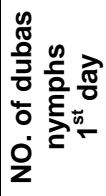 & 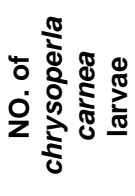 & $\mathbf{R}$ & 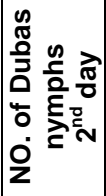 & 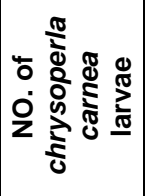 & $\mathbf{R}$ & 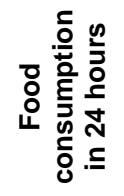 & 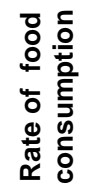 & 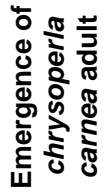 \\
\hline 1 & 50 & 1 & 1 & 30 & 1 & 1 & 20 & $40 \%$ & 1 \\
\hline 2 & 50 & 1 & 2 & 42 & 1 & 2 & 8 & $16 \%$ & \\
\hline 3 & 50 & 1 & 3 & 29 & 1 & 3 & 21 & $42 \%$ & 1 \\
\hline 4 & 50 & 1 & 4 & 40 & 1 & 4 & 10 & $20 \%$ & \\
\hline 5 & 50 & 1 & 5 & 27 & 1 & 5 & 23 & $46 \%$ & 1 \\
\hline $\mathbf{C}$ & 50 & - & $\mathbf{C}$ & 50 & - & $\mathbf{C}$ & - & - & - \\
\hline $\begin{array}{c}\mathrm{M}+\mathrm{S} . \\
\mathrm{Er}\end{array}$ & - & - & - & - & - & - & $16.4 \pm 6.9$ & $32.8 \%$ & - \\
\hline
\end{tabular}

\section{REFERENCES}

Al - Azawi, A. F. (1986). A survey of insect pests of date palm in Qatar, Date palm Journal, 4 , ( 2 ) 247 - 266.

Al-Shamsi, B. H. (2003). Biological Performance of dubas bug Ommatissus lybicus De Berg. (Homoptera: Tropiduchidae) Under Field Conditions and Predicting of its Appearance by using degreeday Model. Thesis, M. Sc. Fac. Agriculture. Univ. Baghdad. PP 151.

Asche, M. and Wilson, M. R. (1989). The palm-feeding plant hopper genus Ommatissus (Homoptera: Fulgoroidea: Tropiduchidae). Systematic Entomology, 14: 2, 127-147.

El-Haidari, H. S. and AI-Hafidh, E. M. T. (1986). Palm and date arthropod pests in the Near East and North Africa (in Arabic). Project for palm \& Date Research Centre in the Near East \& North Africa. Baghdad: FAO Bulletin.

El - Haidari, H. S. (1981). Ommatissus binotatus De Bergevin ( Homoptera :Tropiduchidae ) .Date Palm Journal. P. 133.

EL- Haidari, H. S. (1982). New records of dubas bug Ommatissus binotatus lybicus (De Bergevin) on date palms in Sudan. Date palm Journal, 1 (2): 308.

El-Juhany, L. (2010). Degradation of Date Palm Trees and Date Production in Arab Countries: Causes and Potential Rehabilitation. Australian Journal of Basic and Applied Sciences, 4(8): 3998-40 10. 2010.

Elwan, A., and Al-Tamiemi, S. (1998). Life cycle of dubas bug, Ommatissus binotatus lybicus De berg. (Homoptera: Tropiduchidae) in sultanate of Oman. Egypt. J. Agric. Res. , 77 (4), 7999.

FAO. (1982). Plant Production and Protection: Paper No. 35. Date production and protection. FAO. Rome, Italy, pp: 294.

Hill, D. A. and Waller, J. M. (1990). Pests and Diseases of tropical crops. Vol. 2. Field Handbook. Longman Scientific and Technical, U. K. 432. 
Hussain, A. E. et al.

Hussain, A. A. (1963): Pests of date palms and dates with methods of control in Iraq (Ay) Baghdad: Al- Edara Al- Mahlia Press, 209 p.

Hussain, A. A. (1985). Date palm and Dates and there pests, pp. 216-232, Basra University, Iraq.

Hussain, A. E. (2011): Dubas Bug (Ommatissus lybicus De Berg. Tropiduchidae : Homoptera), A New Pest of Date Palm and Canary Palm in Helwan Governorate - Egypt. Arab Palm conference 2011. The first scientific conference for the development of the date palm and dates sector in the Arab world. 4-7 December.

Hussin, A. E. and Ali, M. A. (1996). New record of the dubas bug, Ommatissus binotatus lybicus De Berg., a threat to date palms in Bahria oases, Egypt Bull. Ent. Soc. Egypt. 74, 1996 (1): 1 - 8.

Klein, M. and Veneztan, A. ( 1985 ). The dubas date tropiduchid. Ommatissus binotatus lybicus, a threat to date palms in Israel. Phytoparasitica, 13 (2): $95-101$.

Kranz, J.; Schmutterer, H. and Koch, W. (1978). Disease, pest and Weeds in Tropical Crops. P. 304-305. John Wiley Sons Ltd. Chichester, U.K.

Lal. O. P. and Naji, A. H. (1997). Observation on some new insect pests and parasites from the Socialist Peoples Libyan Arab Gamahiriya. Rivista diAgricoltura subtropicale e Tropicale. 73 (3-4): $219-232$.

Zohary, D. and M. Hopf. (2000). Domestication of Plants in the Old World $\left(3^{\text {rd }}\right.$ Ed.) Oxford University Press, Oxford, UK.

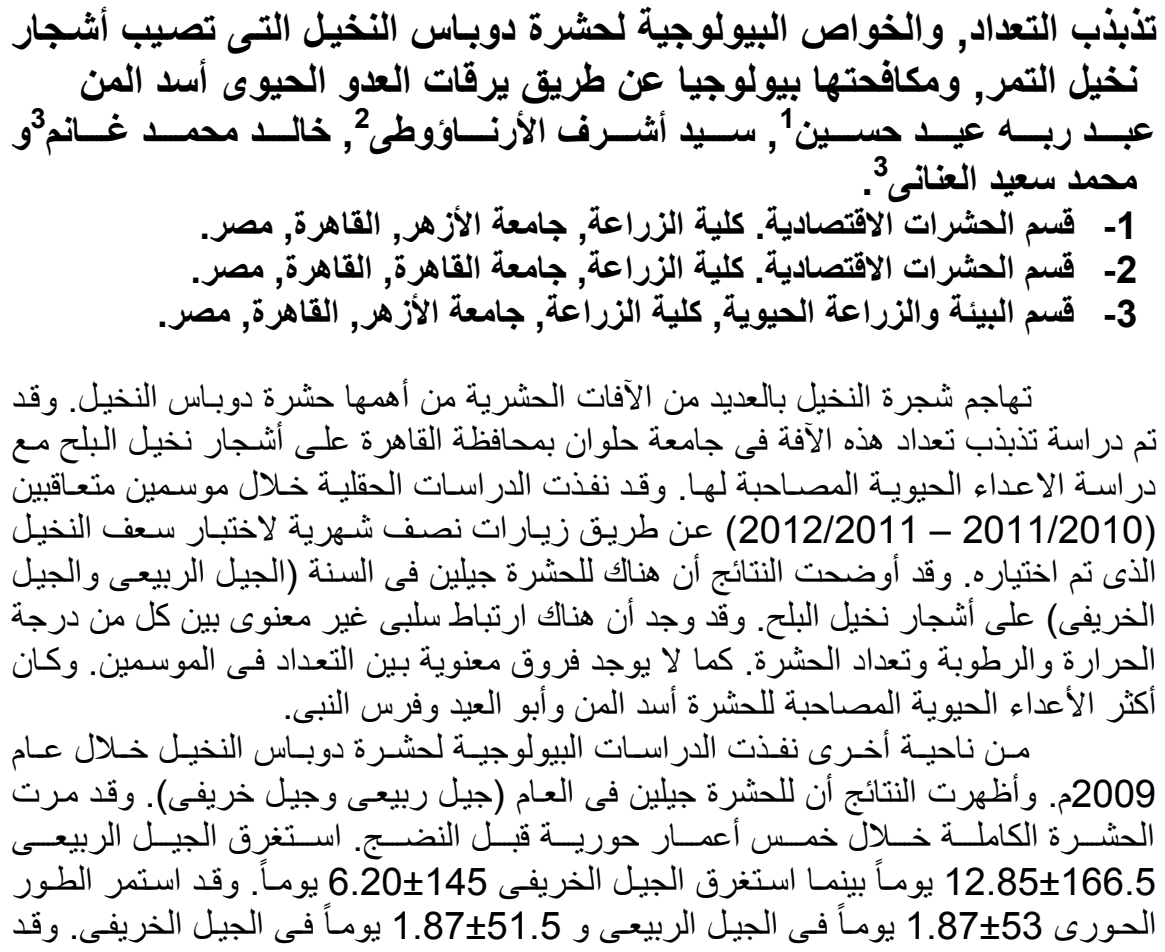




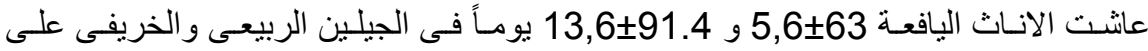

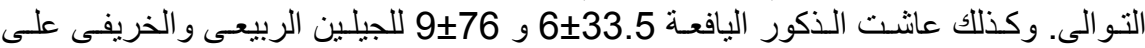

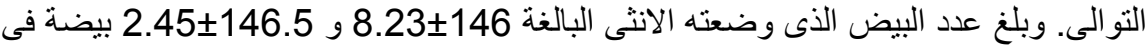

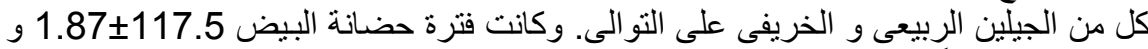

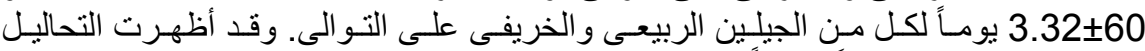

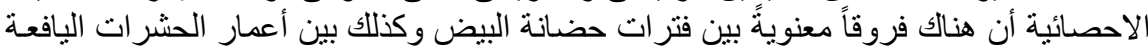

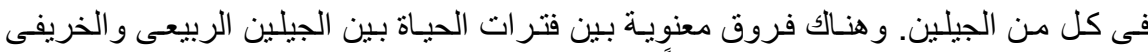

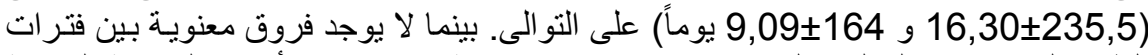

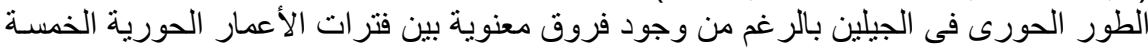

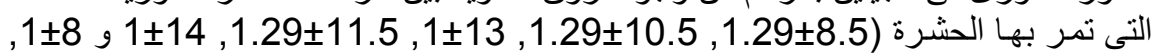

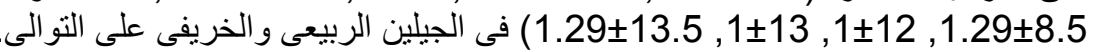

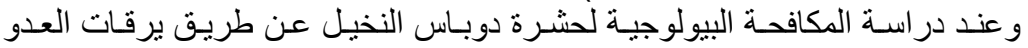

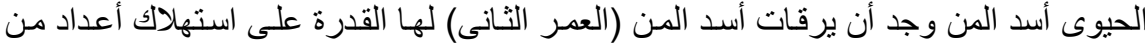

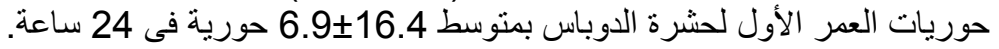

كلية الزراعة - جامعة المنصورة

قام بتحكيم البحث كلية الزراعة - جامعة الازهر 